\title{
Papers
}

\section{Clinical and legal significance of fragmentation of bullets in relation to size of wounds: retrospective analysis}

\author{
Robin Coupland
}

\begin{abstract}
Objective To examine the relation between fragmentation of bullets and size of wounds clinically and in the context of the Hague Declaration of 1899. Design Retrospective analysis of prospectively collected data on hospital admissions.

Setting Hospitals of the International Committee of the Red Cross.

Subjects 5215 people wounded by bullets in armed conflicts (5933 wounds).

Main outcome measures Grade of wound computed from the Red Cross wound classification and presence of bullet fragments on radiography.

Results Of the 347 wounds with fragmentation of bullets, $251(72 \%)$ were large wounds (grade 2 or 3 )that is, those with a clinically detectable cavity. Of the 5586 wounds without fragmentation of bullets, 2915 $(52.1 \%)$ were large wounds. Only $7.9 \%(251 / 3166)$ of large wounds were associated with fragmentation of bullets.

Conclusions Fragmentation of bullets is associated with large wounds, but most large wounds do not contain bullet fragments. In addition, bullet fragments may occur in wounds that are not defined as large. Fragmentation of bullets is neither a necessary nor sufficient cause of large wounds, and surgeons should not diagnose extensive tissue damage because of the presence of fragments on radiography. Such findings also do not necessarily represent the use of bullets which contravene the law of war. Future legislation should take into account not only the construction of bullets but also their potential to transfer energy to the human body.
\end{abstract}

\section{Introduction}

The St Petersburg Declaration of 1868 banned the use of bullets that explode on impact with the human body, and this was the basis of the legal notion of "superfluous injury or unnecessary suffering." In the 1890s concern mounted about the effects on human beings of other bullets, including British dumdum bullets. This concern opened a debate about, on the one hand, the effectiveness of bullets or their stopping power and, on the other hand, how much injury civilised nations should inflict on their enemies. ${ }^{2-5}$ As a result, in the Hague Declaration of 1899, the contracting parties agreed "to abstain from the use of bullets which expand or flatten easily in the human body, such as bullets with a hard envelope which does not entirely cover the core or is pierced with incisions." (Such bullets now have various names such as expanding, soft-point, and hunting; they are best referred to collectively as semi-jacket bullets.) Since then, all military bullets have been covered by a full metal jacket, an example of successful international legislation.

Wounds are caused by transfer of kinetic energy from projectiles to tissues of the body: the greater the transfer of energy the larger the wounds. The nature of the bullets' jackets is only one of the factors determining how much energy is transferred; other factors are velocity, mass, stability in flight, and the length of the track in the body. ${ }^{6}$ Therefore, if bullets with full metal jackets cause large wounds their use in armed conflict may comply with the word of the law but not with the spirit of the law. In other words, legislation about the jacket of bullets may not prevent the effect that gave rise to the concern that prompted the legislation. The issue has been further confused by the different focus of the disciplines concerned. While surgeons have invoked bullets' velocity or kinetic energy as the cause of large wounds, ${ }^{89}$ lawyers and technicians have remained focused on the construction of bullets.

The physical basis of wound ballistics and the causation of large wounds were understood as early as $1908 .{ }^{10}$ However, many wound ballistic experiments have been performed this century with a view to establishing whether certain bullets comply with the Hague Declaration of 1899. The detection of fragments of bullets either on radiography or by shooting a given bullet into simulated soft tissue is assumed to show non-compliance with the treaty or the use of bullets that have not been designed for military use. ${ }^{11-15}$ This assumption is based on another: that the process of fragmentation of bullets is a necessary and sufficient cause of large wounds. Questioning these assumptions and so questioning the clinical and legal significance of fragmentation of bullets requires critical examination of the occurrence of large wounds and the extent to which this is associated with the fragmentation of bullets.

I used the Red Cross wound classification to examine the relation between fragmentation of bullets as detected on clinical radiography and the size of wounds sustained in the field.

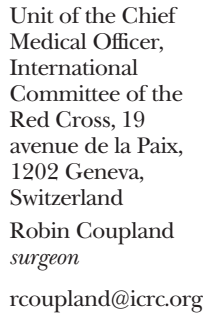

BMJ 1999;319:403-6 


\section{Methods}

\section{Red Cross wound classification}

The Red Cross wound classification permits documentation of the effects of missiles and explosions on people. ${ }^{16-19}$ It is an anatomical classification alone and does not include a physiological variable. In a clinical setting this classification has been used to document the incidence of bullet disruption in armed conflict ${ }^{14}$ and the categories of wounds caused to civilians by hand grenades ${ }^{20}$ and to establish the size of wounds inflicted by conventional weapons. ${ }^{1}$

The box shows the six factors that can be scored for any wound. The M score indicates whether bullets or bullet fragments are visible in a radiograph and is relevant to this study (figs 1 and 2). Wounds are graded from the scores for entry, exit, and cavity to denote size and so reflect energy transfer. The $\mathrm{V}$ and $\mathrm{M}$ scores do not influence the computing of the grade. The correlation between grade and energy transfer or between grade and type of weapon is not precise, but bullets from handguns usually inflict grade 1 wounds and transfer up to $500 \mathrm{~J}$ of energy. ${ }^{6}$ Bullets from shotguns fired at close range would invariably cause wounds of grade 3 and are associated with transfer of more than $1500 \mathrm{~J}$ of energy. ${ }^{6}$ Military rifles can inflict all grades of wound. $^{715}$

\section{Red Cross wound classification}

Factors to be scored

$\mathrm{E}$, entry-Estimate the maximum diameter of the entry wound in centimetres

$\mathrm{X}$, exit-Estimate the maximum diameter of the exit wound in centimetres $(\mathrm{X}=0$ if no exit)

C, cavity-Can the cavity of the wound take two fingers before surgery? This may be obvious before operation or be established only after skin incision. For chest or abdomen wounds it refers to the wound of the chest or abdominal wall

$\mathrm{C}=0$ if cavity cannot take two fingers

$\mathrm{C}=1$ if it can

$\mathrm{F}$, fracture- Is there a fracture?

$\mathrm{F} 0=$ no fracture

$\mathrm{F} 1=$ simple fracture, hole, or insignificant comminution

F2 = clinically significant comminution

$\mathrm{V}$, vital structure-Are brain, viscera, or major vessels injured? Is there breach of dura, pleura, or peritoneum?

$\mathrm{V}=0$ if they are not injured

$\mathrm{V}=1$ if they are

$\mathrm{M}$, metallic body-Are bullets or bullet fragments visible on radiography?

$\mathrm{M}=0$ if there are no metallic bodies

$\mathrm{M}=1$ if there is one metallic body

$\mathrm{M}=2$ if there are two or more metallic bodies

Grading of wounds

Grade 1-Skin wounds of $<10 \mathrm{~cm}(\mathrm{E}+\mathrm{X}<10)$

without a cavity $(\mathrm{C} 0)$ and without a comminuted fracture (F0 or F1)

Grade 2-Skin wounds of $<10 \mathrm{~cm}(\mathrm{E}+\mathrm{X}<10)$ with a cavity (C1) or comminuted fracture (F2)

Grade 3-Skin wounds of $\geqslant 10 \mathrm{~cm}(\mathrm{E}+\mathrm{X} \geqslant 10)$ with a cavity (C1) or comminuted fracture (F2)
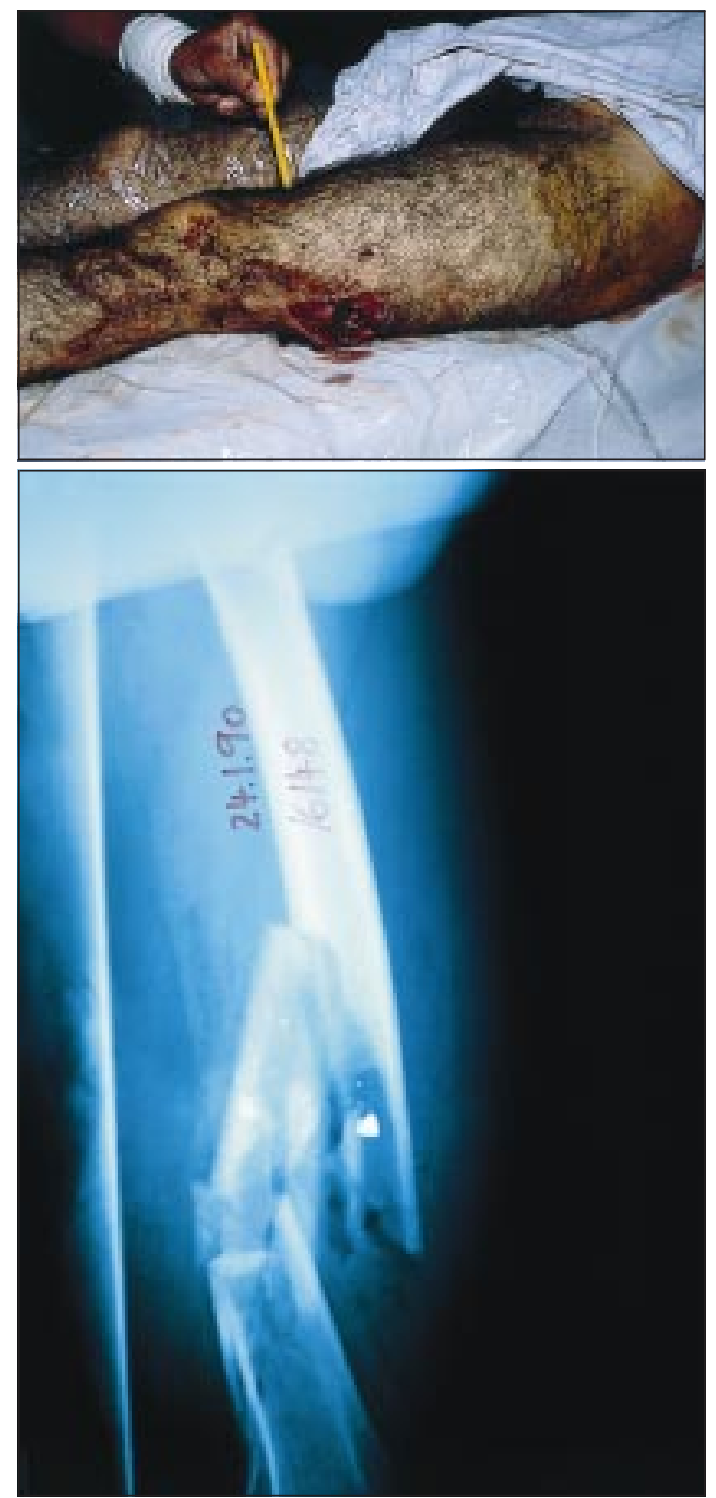

Fig 1 Bullet wound of left thigh. Top: Entry wound is indicated by pen and measured $<1 \mathrm{~cm}$. Exit wound on lateral side of thigh is large and obvious. Bottom: Radiograph shows comminution of femur with one large and several small metallic bullet fragments Wound is grade 2 (scores: $E=1, X=8, C=1, F=2, V=0, M=2$ )

\section{Wound database}

The wound database of the International Committee of the Red Cross originates from a system of data collection which was established in the organisation's independent hospitals in 1991. Included in the information recorded for each of the 26636 patients are the cause of injury and the Red Cross wound classification.

I analysed all records of patients with one or two bullet wounds scored by the Red Cross wound classification by grade of wound or wounds and the corresponding $\mathrm{M}$ scores. I combined wounds of grade 2 and 3 to form a category of large wounds to compare the proportion of wounds associated with fragmentation of bullets.

\section{Results}

A total of 5215 patients had scores for their bullet wounds. Of these 718 had two scored wounds. Thus, 
Grade of wound by M score for 5933 bullet wounds

\begin{tabular}{lrrc} 
& Grade 1 & Grade 2 & Grade 3 \\
\hline $\mathrm{M}=0$ (no bullet fragments) & 1916 & 2021 & 464 \\
\hline $\mathrm{M}=1$ (bullet intact) & 755 & 395 & 35 \\
\hline $\mathrm{M}=2$ (multiple bullet fragments) & 96 & 203 & 48 \\
\hline
\end{tabular}

there were a total of 5933 scored wounds from which the grade could be computed. The table shows the grade of wound by M score.

Of the 347 wounds associated with fragmentation of bullets (total of M2 wounds), 251 (72\%) were large wounds (grade 2 or grade 3 ). Of the 5586 wounds not associated with fragmentation of bullets (total of M0 plus M1 wounds), 2915 (52.1\%) were large wounds. Fragmentation of bullets (M2 wounds only) was associated with $96(3.5 \%)$ of the 2767 grade 1 wounds and with $251(7.9 \%)$ of the 3166 large wounds. Fragmentation of bullets was associated with large wounds (Pearson's $\left.\chi^{2}=53.3, \mathrm{P}<0.0001\right)$.

\section{Discussion}

These results show that fragmentation of bullets and large wounds is associated with large wounds, but fragmentation does not necessarily cause large wounds. Previous assumptions about the significance of fragmentation of bullets are misguided; this conclusion is supported by the fact that $82.1 \%$ of the large wounds occurred without fragmentation of bullets.

\section{Limitations of the study}

This study has several limitations related to the conditions under which the data were collected. A plain radiograph of the wounded part is taken routinely in Red Cross hospitals. A few may not have had this investigation either because the wounds were so serious that the person was taken directly to the operating theatre or because the wound did not require surgical intervention; in such cases the M score would be recorded as zero.

There are no data pertaining to those people who died before reaching hospital. This can be offset against the fact that some Red Cross hospitals admit only those who are more severely wounded; the others find treatment elsewhere. The results are unlikely to be affected by either factor as most of the wounded patients have wounds to their arms or legs that whatever their severity, rarely prevent the person reaching hospital.

Possible observer error must be addressed. The proportion of M2 wounds seen in four Red Cross hospitals in a previous study is higher than reported here. ${ }^{14}$ In that study, data were collected by retrospective review of radiographs. The most likely cause for the lower proportions of M2 wounds in the centralised Red Cross database is that the many surgeons deployed in these hospitals who are responsible for the routine scoring of wounds are not aware that small and less noticeable specks of lead ejected from the base of a full metal jacket bullet ${ }^{6}{ }^{13}$ should also be scored as M2. Multiple pellets from a shotgun cartridge would also be scored as M2; however, in my experience such wounds are rarely seen in Red Cross hospitals.

A bullet may fragment on passing through the metalwork of a vehicle. Whatever the wound or wounds sustained by the person inside the vehicle, a radiograph is likely to show multiple fragments and would correctly be given an M2 score. There is no way to ascertain the proportion of people on the database who were wounded in this way. This could account for some of the M2 scores of the grade 1 wounds.

Although most bullet wounds in this study were most likely inflicted by a Kalashnikov AK47 rifle, it is unclear how the proportions of the grades of wounds or the proportion with M2 wounds would change with different weapons.

\section{Conclusions}

None of these limitations refute the conclusion that fragmentation of bullets is an unreliable indicator of large wounds. Disproving the assumptions about the association between bullet fragmentation and large wounds has important implications. In a clinical setting surgeons should not diagnose extensive tissue damage
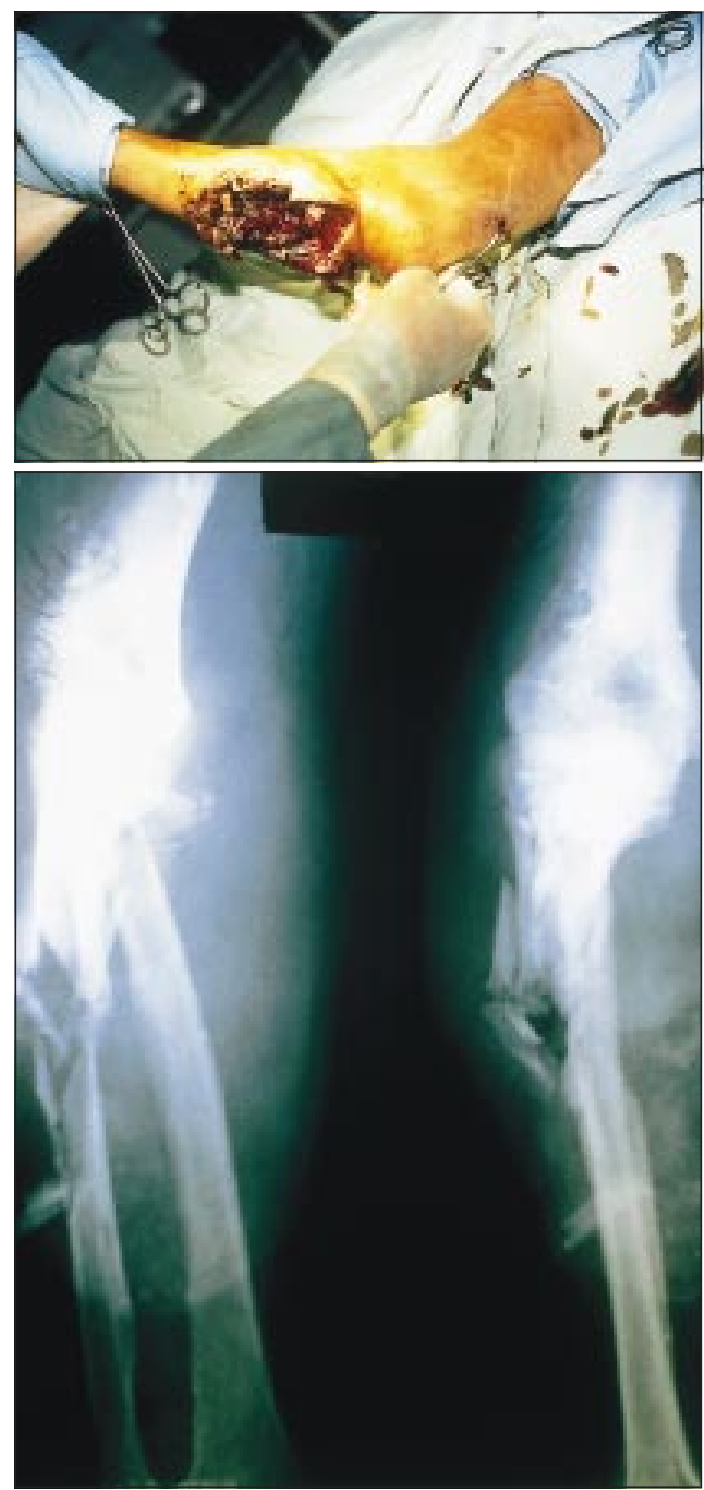

Fig 2 Bullet wound of left arm. Top: Entry wound is just proximal to elbow joint and is indicated by forceps in surgeon's hand. Exit wound in forearm is large and obvious. Bottom: Radiograph shows comminution of forearm bones and no metallic bullet fragments. Wound is grade 3 (scores: $E=1, X=11, C=1, F=2, V=0, M=0$ ) 
breaking; this is particularly the case for bullets with full metal jackets (fig 2).

Legislation about bullets' construction should be

- The use of certain bullets has been prohibited in war

- Wounds from bullets are caused by transfer of kinetic energy from the bullet to the tissues

- The relation between size of wound and fragmentation of bullets can be examined using the Red Cross wound classification system

- Fragments of bullets seen on radiographs of wounds sustained in wars do not necessarily represent large wounds or the use of illegal bullets

- Existing legislation on the construction of bullets should be supplemented by legislation on how much energy is transferred to tissues

because of the presence of bullet fragments on radiography. Likewise, lawyers should not claim that fragmentation of bullets as seen on clinical radiographs or in wound ballistic studies implies contravention of the Hague Declaration of 1899.

The results of this study are explicable by an understanding of wound ballistics. As a bullet passes along its track in the body, it lacerates and damages tissues by doing work on them-that is, by transferring to the tissues the kinetic energy it is carrying. An equal and opposite amount of work is done on the bullet by the tissues. Where along the track this work is done is determined, in part, by the construction of the bullet. A bullet which expands or flattens easily in the human body-that is, a semi-jacket bullet-is likely to cause a large wound because it transfers most of its energy in the first $10 \mathrm{~cm}$ of its track ${ }^{6}$; fragments of the bullet are seen on radiography as a result. A military bullet may, after $10-20 \mathrm{~cm}$ of minimal energy transfer, turn sideways in its track, maximise energy transfer, and be compressed enough to cause it to deform or break ${ }^{6}$; again, fragments may be seen as a result (fig 1). Whatever the construction of a bullet, if enough work is being done in the interaction between the projectile and the tissues, the bullet deforms or breaks. However, enough work can be done to cause a large wound without the bullet deforming or supplemented by legislation about how much kinetic energy is transferred to a soft medium and where along the bullets' tracks this energy is transferred. ${ }^{21}$ In this way, new projectiles could not circumvent the spirit of the law.

Funding: No additional funding.

Competing interests: None declared.

1 Coupland RM, ed. The SIrUS Project:towards a determination of which weapons cause "superfluous injury or unnecessary suffering." Geneva: International Committee of the Red Cross, 1997.

2 Davis HJ. Gunshot injuries in the late Greco-Turkish war with remarks upon modern projectiles. BMJ 1897;ii:1789-93.

3 Ogston A. The wounds produced by modern small-bore bullets: the Dum-dum and the soft-nosed Mauser. BMJ 1898;ii:813-5.

4 Ogston A. Continental criticism of English rifle bullets. BMJ 1899;i:752-7. Ogston A. The Peace Conference and the Dum-dum bullet. BMJ 1899;ii:278-81.

6 Sellier KG, Kneubuehl BP. Wound ballistics. Amsterdam: Elsevier, 1994.

7 Coupland RM. War wounds of limbs: surgical management. Oxford: Butterworth Heinemann, 1993

8 Lindsey D. The idolatry of velocity, or lies, damn lies, and ballistics. J Trauma 1980;20:1068-9.

9 Owen Smith MS. High velocity missile injuries. London: Edward Arnold, 1981.

10 Spencer CG. Gunshot wounds. Oxford: Oxford Medical Publications, 1908.

11 Fackler ML, Surinchak JS, Malinowski JA, Bowen RE. Bullet fragmentation: a major cause of tissue disruption. J Trauma 1984:24:35-9.

12 Fackler ML, Surinchak JS, Malinowski JA, Bowen RE. Wounding potential of the Russian AK74 assault rifle. J Trauma 1984;24:263-6.

13 Cooper GJ, Ryan JM. Interaction of penetrating missiles with tissues: some common misapprehensions and implications for wound management. Br J Surg 1990;77:606-10.

14 Coupland RM, Hoikka V, Sjoeklint OG, Cuenod P, Caudrey GC, Doswald-Beck L. Assessment of bullet disruption in armed conflicts. Lancet 1992:339:35-7.

15 Knudsen PJT, Theilade P. Terminal ballistics of the 7.62mm NATO bullet. Int J Leg Med 1993;106:61-7.

6 Bowyer GW. Afghan war wounded: application of the Red Cross wound classification. J Trauma 1995;38:64-7.

17 Coupland RM. The Red Cross wound classification. Geneva: International Committee of the Red Cross, 1991.

18 Coupland RM. The Red Cross classification of war wounds: the EXCFVM scoring system. World J Surg 1992;16:910-7.

19 Coupland RM. Classification and management of war wounds. In: Johnson CD, Taylor I, eds. Recent advances in surgery. No 17. London: Churchill Livingstone, 1994:121-34.

20 Coupland RM. Hand grenade injuries among civilians. JAMA 1993;270:624-6.

21 Kneubuehl BP. Small caliber weapon systems. In: Expert meeting on certain weapon systems and on implementation mechanisms in international law. Geneva: International Committee of the Red Cross, 1994:26-39.

(Accepted 7 April 1999)

\section{Crossed lines}

It was my mother's third visit to the accident and emergency department in as many months and she was obviously very ill, being weak, dehydrated with fast shallow breathing, very low blood pressure, and a deathly pallor. She had received treatment for about six months for anaemia with folic acid, iron, and blood transfusions.

I was with her as usual for she was 88 and profoundly deaf and I was there for her comfort and as a communications facilitator, though she carried with her everywhere her writing board and dry marker pen.

The curtains parted and the doctor came in. There was, for a while, the familiar problem of Mother wanting to do all the talking, the doctor going about his examination but unable to grasp the idea of deafness, and me tentatively trying to be helpful. After a short period of chaos, during which not a lot of progress was made, I volunteered the additional information. "This illness is making Mother very confused."

The doctor obviously decided to check my diagnosis. He took my mother's writing board and wrote, "What is your name?"

"Alice Whittick"
"How old are you?"

" 88 , I'll be 89 on 4 December."

"Where do you live?"

"46 Denmark Road, South Norwood."

Treachery! How could she do this to me? The doctor, seemingly satisfied that whatever else was wrong with her she was not confused, left the cubicle.

As the curtains closed my mother looked at me with a puzzled look and said, "Why was he interviewing me for a job?"

Mother died just over a week later from myelomonocytic leukaemia.

W K Whittick, Purley, Surrey

We welcome articles up to 600 words on topics such as A memorable patient, A paper that changed my practice, My most unfortunate mistake, or any other piece conveying instruction, pathos, or humour. If possible the article should be supplied on a disk. Permission is needed from the patient or a relative if an identifiable patient is referred to. 